\title{
Urinary cystatin $C$ is diagnostic of acute kidney injury and sepsis, and predicts mortality in the intensive care unit
}

\author{
Maryam Nejat1', John W Pickering1, Robert J Walker2, Justin Westhuyzen'1, Geoffrey M Shaw1,3, \\ Christopher M Frampton ${ }^{1}$ and Zoltán H Endre*1
}

\begin{abstract}
Introduction: To evaluate the utility of urinary cystatin C ( $\mathrm{CCys} C$ ) as a diagnostic marker of acute kidney injury (AKI) and sepsis, and predictor of mortality in critically ill patients.

Methods: This was a two-center, prospective AKI observational study and post hoc sepsis subgroup analysis of 444 general intensive care unit (ICU) patients. UCysC and plasma creatinine were measured at entry to the ICU. AKI was defined as a $50 \%$ or $0.3-\mathrm{mg} / \mathrm{dL}$ increase in plasma creatinine above baseline. Sepsis was defined clinically. Mortality data were collected up to 30 days. The diagnostic and predictive performances of $u C y s C$ were assessed from the area under the receiver operator characteristic curve (AUC) and the odds ratio (OR). Multivariate logistic regression was used to adjust for covariates.
\end{abstract}

Results: Eighty-one (18\%) patients had sepsis, 198 (45\%) had AKI, and 64 (14\%) died within 30 days. AUCs for diagnosis by using UCysC were as follows: sepsis, 0.80 , (95\% confidence interval (Cl), 0.74 to 0.87); $\mathrm{AKI}, 0.70$ (Cl, 0.64 to 0.75 ); and death within 30 days, 0.64 (Cl, 0.56 to 0.72$)$. After adjustment for covariates, uCys C remained independently associated with sepsis, AKI, and mortality with odds ratios (Cl) of 3.43 (2.46 to 4.78), 1.49 (1.14 to 1.95), and 1.60 (1.16 to 2.21), respectively. Concentrations of UCys $C$ were significantly higher in the presence of sepsis $(P<0.0001)$ or $A K I(P<0.0001)$. No interaction was found between sepsis and AKI on the uCysC concentrations $(P=0.53)$.

Conclusions: Urinary cystatin C was independently associated with AKI, sepsis, and death within 30 days.

Trial registration: Australian New Zealand Clinical Trials Registry ACTRN012606000032550.

\section{Introduction}

AKI is a common and serious complication in hospitalized and ICU patients with an ICU incidence of $11 \%$ to $67 \%$, with mortality of $13 \%$ to $36 \%$, depending on the definition of AKI [1-5]. Sepsis is a known cause of AKI, with incidences of $20 \%$ and $26 \%$ and AKI-associated mortality of $30 \%$ and $35 \%[1,6,7]$. The incidence of sepsis in ICUs was $28 \%, 37 \%$, and $39 \%$ in each of three multiple cohort studies, with individual cohorts ranging from $18 \%$ to $73 \%$ $[6,8,9]$. In the SOAP study, ICU mortality ranged from $20 \%$ to $47 \%$ [9]. Among 14 epidemiologic studies, severe sepsis rates (sepsis with organ failure) varied from $6.3 \%$ to

* Correspondence: zoltan.endre@otago.ac.nz

${ }^{1}$ Christchurch Kidney Research Group, Department of Medicine, University of Otago Christchurch, Riccarton Avenue, Christchurch 8140, New Zealand Full list of author information is available at the end of the article
$27.1 \%$, with a mean \pm SD of $10 \pm 4 \%$ and with hospital mortality from $20 \%$ to $59 \%$ [10]. Sepsis also results in a large socioeconomic burden, with increased long-term hospitalization or community care for patients [11].

The early diagnosis of AKI in patients with sepsis would assist in more-effective care for these patients. AKI has traditionally been detected and defined by measuring surrogates of kidney-filtration function, such as plasma creatinine $(\mathrm{pCr})$, urea, and, recently, plasma cystatin $\mathrm{C}$ (pCysC) $[12,13]$. Current plasma surrogates are slow to respond to a change in glomerular filtration rate (GFR), leading to delayed diagnosis. The current standard, plasma creatinine, performs poorly [14,15]. Recent research has focused on novel biomarkers of injury, which have the potential to diagnose AKI much earlier [14,16-19]. Several biomarkers have been detected in 
urine and characterized as early, noninvasive, and sensitive indicators of AKI [19-21].

Cystatin $\mathrm{C}$ is a $13-\mathrm{kDa}$ protein that is normally filtered freely and completely reabsorbed and catabolized within the proximal tubule [12]. $\mathrm{pCysC}$ has been shown to be an early predictor of AKI [15] and an independent predictor of mortality [22,23]. uCysC concentration increases with renal tubular damage, independent of change in GFR $[24,25]$. Six hours after cardiopulmonary-bypass surgery, $\mathrm{uCysC}$ was highly predictive of AKI [21].

This study aimed to determine the diagnostic and predictive value of $\mathrm{uCysC}$ for $\mathrm{AKI}$ and mortality in a general ICU population. We also performed a post hoc analysis of $\mathrm{uCysC}$ as a diagnostic marker of sepsis in this setting.

\section{Materials and methods}

Consecutive patients admitted to the ICU of two large centers (Christchurch and Dunedin, New Zealand) between March 2006 and August 2008, were screened for inclusion. Exclusion criteria are presented in Figure 1. The first sample was taken with presumed consent, as under the protocol for the intervention arm of the EARLYARF trial, this sample had to be taken within 1 hour of entry into ICU, often before a patient's family was available to consent formally [26]. Consent was then obtained from patient or family before the second sample.

The study was approved by the multiregional ethics committee of New Zealand (MEC/050020029) and registered under the Australian Clinical Trials Registry (ACTRN012606000032550 EARLYARF 1[27]). Patients who received the study drug in the interventional arm of the EARLYARF trial were excluded before analysis [26].

Blood and urine samples were collected simultaneously at predetermined time points for all patients: within 1 hour of admission (time 0), 12 and 24 hours later, and daily for the next 7 days. Mortality data were collected up to 30 days.

Cystatin $\mathrm{C}$ concentrations were quantified by using a BNII nephelometer (Dade Behring GmbH, Marburg, Germany) by particle-enhanced immunonephelometric assay [28]. The mean intra-assay coefficient of variation was $4.7 \%$ for both plasma and urinary CysC concentrations, which were measured in batched samples prepared on the same day. Creatinine concentration was determined withthe Jaffe reaction by using Abbott reagents on an Architect ci8000 or an Aeroset analyzer (Abbott Laboratories, Abbott Park, Illinois, U.S.A.), or by using Roche reagents on a Modular P Analyzer (Roche Diagnostics $\mathrm{GmbH}$, Mannheim, Germany).

AKI was defined by using the AKIN (Acute Kidney Injury Network) criterion: an absolute increase in plasma creatinine $(\mathrm{pCr})$ above baseline of at least $0.3 \mathrm{mg} / \mathrm{dL}(26.4$ $\mu \mathrm{mol} / \mathrm{L}$ ) or a percentage increase in $\mathrm{pCr}$ of at least $50 \%$ [29]. AKI status was determined at admission to the ICU (time 0 , AKI on entry) and approximately $48 \mathrm{~h}$ later (AKI in $48 \mathrm{~h}$ ). All references to AKI refer to AKI on entry, unless otherwise stated. Sepsis was defined clinically (and independently) by the attending ICU physicians from the presence of two or more SIRS criteria, or from a suspected or confirmed bacterial or viral infection. Confirmation was by blood, urine, or other appropriate cultures.

Baseline creatinine was taken from preadmission values wherever possible by using the following rules ranked in descending order of preference: (a) The most recent preICU value between 30 and 365 days $(n=86)$ or presurgery value for elective cardiac surgery patients at high risk of AKI $(\mathrm{n}=28)$; (b) pre-ICU value $>365$ days, if the patient was younger than 40 years, and creatinine was stable (within $15 \%$ of the lowest ICU creatinine) $(\mathrm{n}=7)$; (c) pre-ICU value $>365$ days, if it was less than initial creatinine on entry to ICU $(\mathrm{n}=58)$; and (iv) pre-ICU value at 3 to 39 days if it was less than the initial creatinine on entry to the ICU and not obviously AKI $(\mathrm{n}=45)$. If a preadmission creatinine was not available, then the lowest value of either the initial creatinine on entry to ICU, the final creatinine measured in 7 days or at 30 days was used $(n=220)$, on the assumption that a true baseline was not likely to be higher than this minimum and that the alternative of estimating baseline creatinines by back-calculation with the MDRD formula would result in an overestimation of the prevalence of AKI [30,31].

Results were expressed as mean \pm standard deviation (SD) for normally distributed variables, or median and interquartile range (IQR) for variables not normally distributed. All concentrations refer to time-of-admission (time 0) samples, unless otherwise stated. Diagnostic and predictive values were assessed $a$ priori for biomarkers on entry to the ICU by the area under the receiver operator characteristic curve (AUC) and by the odds ratio (OR). Both are presented with a $95 \%$ confidence interval $(\mathrm{CI})$ and probability $(P) . P$ values $<0.05$ were considered significant. Correlations were calculated nonparametrically by Spearman's method.

For each outcome (AKI, sepsis, and mortality), urinary and plasma cystatin $\mathrm{C}$ and creatinine, age, gender, hypotension within 1 hour of entry to the ICU, and APACHE II subcategory scores, were assessed with univariate analysis (for continuous variables, a $t$ test or a Mann-Whitney $U$ test, and for categoric variables, a $X^{2}$ test). For analysis, APACHE II subcategory scores were transformed to categoric variables according to whether they were normal $(0$, APACHE II subcategory $=0)$ or not normal (1, APACHE II subcategory $>0$ ). Data were shown for APACHE II subcategories with $P<0.2$ for all outcomes. After univariate analysis, a multivariate logistic regression was used to adjust for covariates. Variables were included in the regression model if they were signif- 


\section{Patients Screened}

\section{Excluded}

Exclusion Criteria

1. under 16 years of age

2. without an indwelling urinary catheter

3. had obvious hematuria, rhabdomyolysis and/or myoglobinuria, or polycythemia $(\mathrm{Hb}>165 \mathrm{~g} / \mathrm{l}$ or $\mathrm{Hct}>48$ in women and $\mathrm{Hb}>185 \mathrm{~g} / \mathrm{l}$ or $\mathrm{Hct}>52$ in men)

4. receiving cytotoxic chemotherapy or renal replacement therapy (RRT), or assessed to need RRT within 48 hours

5. expected to leave ICU within 24 hours

6. not expected to survive 72 hours

7. had already experienced a greater than three-fold rise in plasma creatinine from a known baseline or had a urine output less than $0.3 \mathrm{ml} / \mathrm{kg} / \mathrm{h}$ for $>6 \mathrm{hrs}$ (anuric)

8. no consent

9. received study drug

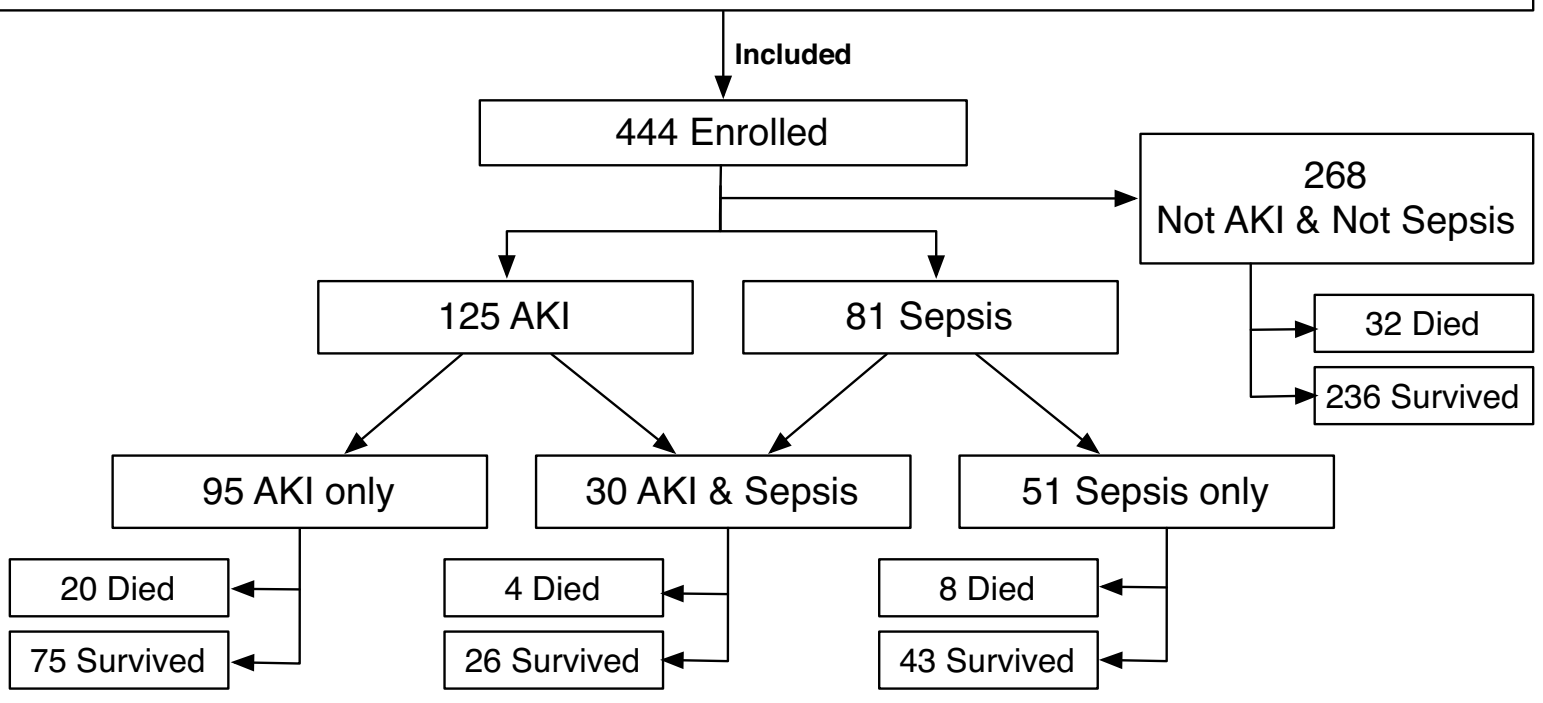

Figure 1 Patient flow.

icant at $P<0.2$ under univariate analysis. No more than one covariate per 10 patients with the outcome was included. For the sepsis logistic regression model $\mathrm{uCysC}$, $\mathrm{pCysC}, \mathrm{uCr}$, gender, hypotension, and APACHE II subcategories respiratory rate and rectal temperature were included. For the AKI model, uCysC, pCysC, uCr, age, hypotension, APACHE II subcategories respiratory rate, white blood cell (WBC) count, and arterial $\mathrm{pH}$ were included. Because $\mathrm{pCr}$ forms part of the definition of AKI, it was not included in the multivariate analysis despite being significantly associated with AKI. For mortality, uCysC, pCysC, age, gender, sepsis, and AKI were included in the model. Because sepsis was included in this model, APACHE II subcategory scores known to be associated with sepsis (respiratory rate and arterial $\mathrm{pH}$ ) were not considered. Variables that were not normally distributed underwent logarithmic transformation (base 10) before inclusion in the model. The odds ratio for a 1- unit increase in a variable results from the logistic regression model. For log-transformed continuous variables, the odds ratio is interpreted as the odds ratio for a 10-fold increase in the variable.

We defined two cut points. The "optimal cut point" is the $\mathrm{uCysC}$ concentration at the point on the ROC curve closest to $(0,1)$, that is, to a 1 -specificity of 0 and a sensitivity of 1 . As each test has a differently shaped ROC curve, the $\mathrm{uCys} C$ concentration for this optimal cut point will be different in each case. The "above-normal cut point" $(0.1 \mathrm{mg} / \mathrm{dL})$, was the upper limit of the normal range of $\mathrm{uCysC}$ and was the same in all tests [32]. Twoway ANOVA was used to assess the effects of AKI and sepsis on urinary cystatin C. Analysis was performed with SPSS version 16 (SPSS Inc., Chicago, IL, USA) and GraphPad Prism 5.0a (GraphPad Software, San Diego, CA, USA). 


\section{Results}

\section{Baseline characteristics}

Between 5 March 2006 and 8 July 2008, 3,966 patients were screened, of whom 3,522 failed inclusion criteria or met exclusion criteria or were excluded from this analysis because they received study drug in the intervention arm of the associated randomized control trial $(n=84,[26])$ leaving 444 enrolled (Figure 1); patients who received placebo remain included here $(\mathrm{n}=78)$. Most exclusions $(\sim 80 \%)$ were for patients expected to leave the ICU within 24 hours. On entry to the ICU, 81 (18.2\%) had a clinical diagnosis of sepsis, 74 (19.1\%) had recently had cardiopulmonary bypass surgery, and 46 (10.4\%) were admitted after a cardiac arrest. Eighty-five (19.1\%) patients had an estimated glomerular filtration rate before to entry to the ICU of $<60 \mathrm{ml} / \mathrm{min}$, and 125 (28.2\%) initially had AKI. Sixty-four (14.4\%) patients died within 30 days. The mean age was $60 \pm 18$ years and 39\% were women. Mean total APACHE II score was $17.7 \pm$ 6.3. Forty-eight (10.8\%) patients were diabetic, and 154 (34.6\%) had a past medical history of hypertension. Christchurch patients comprised 61.3\%, and Dunedin patients, $38.7 \%$ of the cohort. Further clinical characteristics according to subgroups of patients with and without AKI or sepsis are presented in Tables 1 and 2. The cohort is described in greater detail in Endre et al. [26].

The sepsis population $(\mathrm{n}=81)$ had a slightly lower baseline creatinine $(P=0.028)$, were more likely to be female patients $(P=0.095)$, and stayed longer in the ICU $(P<0.001)$ (Table 1$)$. Twenty-eight percent of sepsis patients were taking antibiotics on entry to the ICU. Within the ICU, 56\% required central venous catheters; $59 \%$, vasopressors; and $84 \%$, mechanical ventilation. Not all cultures were definitely positive. However, among those with positive cultures (blood, urine, cerebrospinal fluid, abscess fluid, or ascitic fluid), microorganisms detected included Staphylococcus sp., Streptococcus sp., Escherichia coli, Candida albicans, Neisseria meningitidis, Pseudomonas aeruginosa, Seratia sp., Chlamydia sp., and Legionella pneumoniae.

\section{Association between uCys $\mathrm{C}$ and $\mathrm{pCys} \mathrm{C}$ and sepsis}

Concentrations of $\mathrm{uCysC}$ were significantly higher in the sepsis group than the nonsepsis group (Table 1). uCysC was diagnostic of sepsis (AUC $=0.80$; CI, 0.74 to 0.87 ), with an optimal cut point of $0.24 \mathrm{mg} / \mathrm{L}$ (Table 3). After adjustment for covariates, uCysC remained independently associated with sepsis. The adjusted odds ratio of 3.43 corresponds to a $243 \%$ increase in the odds of having sepsis for a 10 -fold greater uCysC concentration. Sepsis was more than 8 times more likely in patients with uCysC above the optimal cut point (Table 3 ).
Although the $\mathrm{pCysC}$ concentrations were significantly higher among patients with sepsis, than without (Table 1 ), and pCysC was mildly diagnostic of sepsis (AUC = 0.60 ; $\mathrm{CI}, 0.53$ to 0.67 ), pCysC was not independently associated with sepsis after adjustment for covariates $(P=$ $0.75)$.

\section{Association between cystatin C and AKI}

Concentrations of $\mathrm{uCysC}$ were significantly higher in patients with AKI (Table 1). The AUC for AKI was 0.70 (CI, 0.64 to 0.75 ), and the optimal cut point was at 0.12 $\mathrm{mg} / \mathrm{L}$ (Table 3). After adjustment for covariates, uCysC remained independently associated with AKI, with an adjusted odds ratio of 1.49 for a 10 -fold greater concentration. Patients with uCysC above the optimal cut point were more than twice as likely to have AKI than were those below this cut point. The diagnostic performance of the logistic regression model was considerably better than that for uCysC alone, with an AUC of 0.84; CI, 0.79 to 0.89 (Table 3 ). In patients without sepsis, $\mathrm{uCys} C$ was correlated with the severity of renal dysfunction, as defined by percentage increase in $\mathrm{pCr}$ from baseline $(r=$ $0.45 ; P<0.0001)$. In patients without AKI on entry, $\mathrm{uCysC}$ was not predictive of AKI in 48 hours (AUC = 0.54 ; CI, 0.46 to 0.62 .)

As expected, the pCysC concentrations were significantly higher in patients with AKI than without (Table 1) and were diagnostic of AKI $(\mathrm{AUC}=0.78$; CI, 0.73 to 0.83 ; $P<0.0001)$.

\section{Association between uCys $\mathrm{C}$ and mortality}

Concentrations of $\mathrm{uCysC}$ were significantly higher in those who died within 30 days than in survivors (Table 2). The AUC for death within 30 days was 0.64 (CI, 0.56 to 0.72 ), and the optimal cut point was $0.09 \mathrm{mg} / \mathrm{L}$ (Table 3). After adjustment for covariates, uCys $\mathrm{C}$ remained independently associated with mortality, with an adjusted odds ratio of 1.60 for a 10 -fold greater concentration (Table 3). Patients with uCysC greater than the optimal cut point were more than twice as likely to die within 30 days than were those below the cut point. In contrast to urinary data, ROC analysis showed that the AUC of pCysC for mortality was 0.62 (CI, 0.53 to 0.72 ) [13]. However, after adjustment for covariates, pCysC did not remain independently associated with mortality $(P=$ $0.60)$.

\section{Association between uCys $\mathrm{C}, \mathrm{AKI}$ and sepsis}

The median (IQR) uCysC for patients with sepsis and AKI (5.48 (0.85-13.05) mg/L) was 4 times higher than that in patients with sepsis without AKI (1.38 (0.08-9.98) mg/ L) (Figure 2a), but this difference in distribution was not significant $(P=0.11)$. The median uCysC concentration 
Table 1: Clinical characteristics and cystatin C concentrations on admission to the ICU for cohorts with and without sepsis or AKI

\begin{tabular}{|c|c|c|c|c|c|c|}
\hline & $\begin{array}{l}\text { Sepsis } \\
(n=81)\end{array}$ & $\begin{array}{l}\text { Not sepsis } \\
(n=363)\end{array}$ & $P$ & $\begin{array}{l}\text { AKI } \\
(n=125)\end{array}$ & $\begin{array}{l}\text { Not AKI } \\
(n=319)\end{array}$ & $P$ \\
\hline Age, years & $58 \pm 18$ & $60 \pm 18$ & 0.28 & $62 \pm 15$ & $58 \pm 18$ & 0.12 \\
\hline Female & $38(47 \%)$ & $134(36 \%)$ & 0.095 & $45(36 \%)$ & $127(40 \%)$ & 0.46 \\
\hline Baseline $\mathrm{pCr}, \mathrm{mmol} / \mathrm{L}$ & $\begin{array}{l}0.07 \\
(0.06-0.09)\end{array}$ & $\begin{array}{l}0.08 \\
(0.06-0.10)\end{array}$ & 0.028 & $\begin{array}{l}0.08 \\
(0.06-0.10)\end{array}$ & $\begin{array}{l}0.07 \\
(0.06-0.09)\end{array}$ & 0.33 \\
\hline Total APACHE II score & $17.4 \pm 6.2$ & $17.8 \pm 6.4$ & 0.57 & $19.5 \pm 6.3$ & $17 \pm 6.2$ & $<0.001$ \\
\hline $\begin{array}{l}\text { Heart rate APACHE Ila } \\
<70 \text { or }>109 \text { beats } / \text { minute }\end{array}$ & $63(77 \%)$ & $263(73 \%)$ & 0.33 & 91 (73\%) & $235(74 \%)$ & 0.85 \\
\hline $\begin{array}{l}\text { Respiratory rate APACHE IIa } \\
<12 \text { or }>24 \text { breaths/minute }\end{array}$ & $48(61 \%)$ & $159(44 \%)$ & 0.012 & $51(41 \%)$ & $156(49 \%)$ & 0.12 \\
\hline $\begin{array}{l}\text { WBC APACHE } \|^{a} \\
<3,000 \text { or }>14,900 / \mathrm{mm}^{3}\end{array}$ & $42(52 \%)$ & 167 (46\%) & 0.34 & $74(59 \%)$ & $135(42 \%)$ & 0.001 \\
\hline $\begin{array}{l}\text { Rectal temperature APACHE II } \\
<36.0^{\circ} \mathrm{C} \text { or }>38.4^{\circ} \mathrm{C}\end{array}$ & $32(40 \%)$ & $225(62 \%)$ & 0.0003 & $71(57 \%)$ & $186(58 \%)$ & 0.77 \\
\hline $\begin{array}{l}\text { Arterial pH Apache Ila } \\
<7.33 \text { or }>7.49\end{array}$ & $56(70 \%)$ & $252(69 \%)$ & 0.96 & $100(80 \%)$ & $206(65 \%)$ & 0.002 \\
\hline Hypotension before ICU & $27(33 \%)$ & $183(50 \%)$ & 0.005 & $76(61 \%)$ & $134(42 \%)$ & $<0.0001$ \\
\hline Vasopressor/Catecholamine use & $48(60 \%)$ & $235(65 \%)$ & 0.43 & $82(65 \%)$ & $201(63 \%)$ & 0.91 \\
\hline Urine output (first 6 hours), $\mathrm{mL}$ & $\begin{array}{l}454 \\
(294-611)\end{array}$ & $\begin{array}{l}570 \\
(320-960)\end{array}$ & 0.005 & $\begin{array}{l}410 \\
(254-645)\end{array}$ & $\begin{array}{l}592 \\
(340-996)\end{array}$ & $<0.0001$ \\
\hline Mechanical ventilation ${ }^{b}$ & $68(84 \%)$ & $326(90 \%)$ & 0.13 & $108(86 \%)$ & $286(90 \%)$ & 0.33 \\
\hline Length of mechanical ventilation, ${ }^{b}$ days & $3.8 \pm 2.7$ & $2.7 \pm 2.4$ & $<0.001$ & $3.4 \pm 2.6$ & $2.8 \pm 2.4$ & 0.025 \\
\hline $\mathrm{uCysC}, \mathrm{mg} / \mathrm{L}$ & $\begin{array}{l}2.45 \\
(0.26-10.7)\end{array}$ & $\begin{array}{l}0.08 \\
(0.03-0.23)\end{array}$ & $<0.0001$ & $\begin{array}{l}0.45 \\
(0.09-2.54)\end{array}$ & $\begin{array}{l}0.07 \\
(0.03-0.28)\end{array}$ & $<0.0001$ \\
\hline $\mathrm{uCr}, \mathrm{mmol} / \mathrm{L}$ & $\begin{array}{l}7.00 \\
(4.6-11.8)\end{array}$ & $\begin{array}{l}4.70 \\
(2.2-9.2)\end{array}$ & 0.0006 & $\begin{array}{l}7.40 \\
(3.8-11.6)\end{array}$ & $\begin{array}{l}4.60 \\
(2.1-8.3)\end{array}$ & $<0.0001$ \\
\hline $\mathrm{pCr}, \mathrm{mmol} / \mathrm{L}$ & $\begin{array}{l}0.09 \\
(0.07-0.14)\end{array}$ & $\begin{array}{l}0.09 \\
(0.07-0.12)\end{array}$ & 0.49 & $\begin{array}{l}0.14 \\
(0.11-0.18)\end{array}$ & $\begin{array}{l}0.08 \\
(0.07-0.10)\end{array}$ & $<0.0001$ \\
\hline $\mathrm{pCysC}, \mathrm{mg} / \mathrm{L}$ & $\begin{array}{l}0.98 \\
(0.78-1.41)\end{array}$ & $\begin{array}{l}0.81 \\
(0.65-1.22)\end{array}$ & 0.034 & $\begin{array}{l}1.26 \\
(0.88-1.81)\end{array}$ & $\begin{array}{l}0.76 \\
(0.62-1.02)\end{array}$ & $<0.0001$ \\
\hline Length of ICU stay, hours & $\begin{array}{l}121 \\
(51-310)\end{array}$ & $\begin{array}{l}68 \\
(42-159)\end{array}$ & $<0.001$ & $\begin{array}{l}92 \\
(54-162)\end{array}$ & $\begin{array}{l}67 \\
(42-160)\end{array}$ & 0.006 \\
\hline Dead within 30 days & $12(15 \%)$ & $52(14 \%)$ & 0.91 & $24(19 \%)$ & $40(13 \%)$ & 0.07 \\
\hline AKI & $30(37 \%)$ & $95(26 \%)$ & 0.05 & $125(100 \%)$ & 0 & - \\
\hline Sepsis & 81 (100\%) & 0 & - & 30 (24\%) & $51(16 \%)$ & 0.05 \\
\hline
\end{tabular}

All data are on admission to the intensive care unit, with the exception of Baseline $\mathrm{pCr}$, the timing of which is described in the text. Presented for categoric variables are number, $\mathrm{n}(\%)$, and for continuous variables normally distributed, mean $\pm \mathrm{SD}$, and not normally distributed, median (interquartile range). AKI, acute kidney injury on admission to intensive care; uCysC, urinary cystatin $\mathrm{C} ; \mathrm{uCr}$, urinary creatinine; $\mathrm{pCysC}$, plasma cystatin $\mathrm{C} ; \mathrm{pCr}$, plasma creatinine; $\mathrm{WBC}$, white blood cell.

${ }^{a}$ APACHE II are the numbers $(n)$ and percentage of patients with non-normal (non-zero) scores for each of the APACHE II subcategories listed.

bWithin 7 days of entry to ICU. 
Table 2: Clinical characteristics and cystatin C concentrations on admission to the ICU, and 30-day outcomes for surviving and dying cohorts with and without both sepsis and AKI

\begin{tabular}{|c|c|c|c|c|c|c|}
\hline & $\begin{array}{l}\text { Dead within } 30 \\
d \\
(n=64)\end{array}$ & $\begin{array}{l}\text { Alive at } 30 \mathrm{~d} \\
(\mathrm{n}=\mathbf{3 8 0})\end{array}$ & $P$ & $\begin{array}{l}\text { Sepsis and AKI } \\
(n=30)\end{array}$ & $\begin{array}{l}\text { Not sepsis } \\
\text { and not AKI } \\
(\mathrm{n}=268)\end{array}$ & $P$ \\
\hline Age, years & $64 \pm 17$ & $58 \pm 18$ & 0.16 & $58 \pm 18$ & $59 \pm 18$ & 0.76 \\
\hline Female & $31(48 \%)$ & $141(37 \%)$ & 0.09 & $12(40 \%)$ & $101(38 \%)$ & 0.81 \\
\hline Baseline $\mathrm{pCr}, \mathrm{mmol} / \mathrm{L}$ & $\begin{array}{l}0.08 \\
(0.06-0.10)\end{array}$ & $\begin{array}{l}0.08 \\
(0.06-0.09)\end{array}$ & 0.13 & $\begin{array}{l}0.07 \\
(0.06-0.09)\end{array}$ & $\begin{array}{l}0.08 \\
(0.06-0.09)\end{array}$ & 0.32 \\
\hline Total APACHE II score & $22 \pm 6.9$ & $17 \pm 5.9$ & $<0.0001$ & $18.5 \pm 7.1$ & $17.1 \pm 6.3$ & 0.25 \\
\hline $\begin{array}{l}\text { Heart Rate APACHE IIa } \\
<70 \text { or }>109 \text { beats/minute }\end{array}$ & $54(84 \%)$ & $272(72 \%)$ & 0.32 & $24(80 \%)$ & $196(73 \%)$ & 0.42 \\
\hline $\begin{array}{l}\text { Respiratory rate APACHE IIa } \\
<12 \text { or }>24 \text { breaths/minute }\end{array}$ & $23(36 \%)$ & $184(48 \%)$ & 0.06 & $16(53 \%)$ & $124(46 \%)$ & 0.46 \\
\hline $\begin{array}{l}\text { WBC APACHE IIa } \\
<3,000 \text { or }>14,900 / \mathrm{mm}^{3}\end{array}$ & $32(50 \%)$ & 177 (47\%) & 0.61 & $16(53 \%)$ & $109(41 \%)$ & 0.18 \\
\hline $\begin{array}{l}\text { Rectal temperature APACHE IIa } \\
<36.0^{\circ} \mathrm{C} \text { or }>38.4^{\circ} \mathrm{C}\end{array}$ & $38(59 \%)$ & $219(58 \%)$ & 0.80 & $12(40 \%)$ & $166(62 \%)$ & 0.032 \\
\hline $\begin{array}{l}\text { Arterial } \mathrm{pH} \text { Apache II } \\
<7.33 \text { or }>7.49\end{array}$ & $52(81 \%)$ & $254(67 \%)$ & 0.02 & $22(73 \%)$ & $173(65 \%)$ & 0.34 \\
\hline Hypotension before the ICU & $32(50 \%)$ & $178(47 \%)$ & 0.64 & $14(47 \%)$ & $121(45 \%)$ & 0.88 \\
\hline Vasopressor/Catecholamine use & $43(67 \%)$ & $240(63 \%)$ & 0.38 & $22(73.3)$ & $175(65 \%)$ & 0.38 \\
\hline Urine output (first 6 hours), $\mathrm{mL}$ & $\begin{array}{l}395 \\
(209-785)\end{array}$ & $\begin{array}{l}560 \\
(331-910)\end{array}$ & 0.01 & $\begin{array}{l}382 \\
(229-546)\end{array}$ & $\begin{array}{l}626 \\
(358-1,020)\end{array}$ & 0.001 \\
\hline Mechanical ventilation ${ }^{b}$ & $59(92 \%)$ & $335(88 \%)$ & 0.35 & $22(73 \%)$ & $240(90 \%)$ & 0.006 \\
\hline Length of mechanical ventilation, ${ }^{b}$ days & $3.5 \pm 2.3$ & $2.8 \pm 2.5$ & 0.06 & $3.6 \pm 3.0$ & $2.6 \pm 2.3$ & 0.019 \\
\hline uCysC, mg/L & $\begin{array}{l}0.32 \\
(0.08-2.21)\end{array}$ & $\begin{array}{l}0.08 \\
(0.04-0.68)\end{array}$ & 0.0004 & $\begin{array}{l}5.48 \\
(0.85-13.05)\end{array}$ & $\begin{array}{l}0.06 \\
(0.02-0.15)\end{array}$ & $<0.0001$ \\
\hline $\mathrm{uCr}, \mathrm{mmol} / \mathrm{L}$ & $\begin{array}{l}6.10 \\
(2.55-9.57)\end{array}$ & $\begin{array}{l}5.3 \\
(2.43-9.947)\end{array}$ & 0.94 & $\begin{array}{l}8.85 \\
(5.30-13.13)\end{array}$ & $\begin{array}{l}4.05 \\
(1.90-7.80)\end{array}$ & $<0.0001$ \\
\hline $\mathrm{pCr}, \mathrm{mmol} / \mathrm{L}$ & $\begin{array}{l}0.09 \\
(0.07-0.13)\end{array}$ & $\begin{array}{l}0.09 \\
(0.07-0.12)\end{array}$ & 0.64 & $\begin{array}{l}0.15 \\
(0.10-0.18)\end{array}$ & $\begin{array}{l}0.08 \\
(0.07-0.10)\end{array}$ & $<0.0001$ \\
\hline
\end{tabular}


Table 2: Clinical characteristics and cystatin C concentrations on admission to the ICU, and 30-day outcomes for surviving and dying cohorts with and without both sepsis and AKI (Continued)

\begin{tabular}{|c|c|c|c|c|c|c|}
\hline $\mathrm{pCysC}, \mathrm{mg} / \mathrm{L}$ & $\begin{array}{l}1.0 \\
(0.76-1.44)\end{array}$ & $\begin{array}{l}0.83 \\
(0.65-1.18)\end{array}$ & 0.01 & $\begin{array}{l}1.32 \\
(0.93-1.90)\end{array}$ & $\begin{array}{l}0.74 \\
(0.61-1.00)\end{array}$ & $<0.0001$ \\
\hline Length of ICU stay, hours & $\begin{array}{l}100 \\
(54-162)\end{array}$ & $\begin{array}{l}70 \\
(42-183)\end{array}$ & 0.37 & $\begin{array}{l}112 \\
(58-334)\end{array}$ & $\begin{array}{l}62 \\
(10-144)\end{array}$ & 0.004 \\
\hline Dead within 30 days & 64 (100\%) & 0 & & $4(13 \%)$ & $32(12 \%)$ & 0.83 \\
\hline AKI & $24(38 \%)$ & $101(27 \%)$ & 0.07 & $30(100 \%)$ & 0 & \\
\hline Sepsis & $12(19 \%)$ & $69(18 \%)$ & 0.9 & $30(100 \%)$ & 0 & \\
\hline
\end{tabular}

All data are on admission to the intensive care unit, with the exception of Baseline $\mathrm{pCr}$, the timing of which is described in the text. Presented for categoric variables are number, $n$ (\%) and for

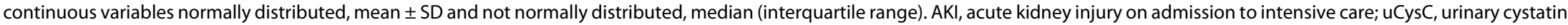
$\mathrm{C} ; \mathrm{uCr}$, urinary creatinine; $\mathrm{PCysC}$, plasma cystatin $\mathrm{C} ; \mathrm{pCr}$, plasma creatinine; $\mathrm{WBC}$, white blood cell.

aAPACHE II are the numbers $(n)$ and percentage of patients with non-normal (non-zero) scores for each of the APACHE II subcategories listed.

bWithin 7 days of entry to ICU. 
Table 3: Association of urinary cystatin C with sepsis, acute kidney injury, and mortality

\begin{tabular}{|c|c|c|c|}
\hline & Sepsis & AKI & Mortality \\
\hline Unadjusted AUC (95\% Cl) & 0.80 (0.74 to 0.87$)$ & 0.70 (0.64 to 0.75$)$ & 0.64 (0.56 to 0.72 ) \\
\hline Optimal cut point (mg/L) & 0.24 & 0.12 & 0.09 \\
\hline Sensitivity $(95 \% \mathrm{Cl})$ & $0.76(0.65$ to 0.84$)$ & 0.67 (0.58 to 0.75$)$ & 0.71 (0.66 to 0.76$)$ \\
\hline Specificity $(95 \% \mathrm{Cl})$ & $0.76(0.70$ to 0.80$)$ & 0.64 (0.58 to 0.70$)$ & 0.53 (0.39 to 0.65$)$ \\
\hline Positive predictive value $(95 \% \mathrm{Cl})$ & 0.41 (0.33 to 0.48$)$ & 0.42 (0.35 to 0.49$)$ & $0.20(0.15$ to 0.27$)$ \\
\hline Negative predictive value $(95 \% \mathrm{Cl})$ & 0.93 (0.90 to 0.96$)$ & 0.83 (0.78 to 0.88$)$ & 0.92 (0.87 to 0.94$)$ \\
\hline \multicolumn{4}{|l|}{ Adjusted odds ratios $(95 \% \mathrm{Cl})$} \\
\hline For a 10 -fold greater concentration & $3.43(2.46 \text { to } 4.78)^{a}$ & $1.49(1.14 \text { to } 1.95)^{\mathrm{b}}$ & $1.60(1.16 \text { to } 2.21)^{c}$ \\
\hline$>$ Optimal cut point & $8.61(4.65 \text { to } 16.0)^{a}$ & $2.45(1.43 \text { to } 4.20)^{\mathrm{b}}$ & $2.56(1.38 \text { to } 4.78)^{c}$ \\
\hline $\begin{array}{l}>\text { Above-normal cut point }(0.1 \mathrm{mg} / \\
\text { L) }\end{array}$ & $4.98(2.56 \text { to } 9.69)^{a}$ & $2.35(1.36 \text { to } 4.05)^{\mathrm{b}}$ & $2.28(1.24 \text { to } 4.19)^{c}$ \\
\hline $\begin{array}{l}\text { Logistic regression model AUC } \\
(95 \% \mathrm{Cl})\end{array}$ & $0.84(0.78 \text { to } 0.90)^{a}$ & $0.84(0.79 \text { to } 0.89)^{\mathrm{b}}$ & $0.68(0.60 \text { to } 0.75)^{c}$ \\
\hline
\end{tabular}

was many times (20 to 30 ) lower in the nonsepsis population. Within this population, a significant difference was noted between patients with AKI $(0.18(0.07-1.62) \mathrm{mg} / \mathrm{L})$ compared with patients without AKI (0.06 (0.02-0.15) $\mathrm{mg} / \mathrm{L} ; P<0.0001$ ) (Figure $2 \mathrm{a})$. No interactive effect was seen between sepsis and AKI $(P=0.53)$, suggesting that the increases in uCysC concentrations due to AKI and sepsis are additive.

\section{Association between uCys $C$, mortality, and sepsis}

$\mathrm{uCys} C$ concentrations were higher on admission in those without sepsis who died within 30 days $(0.15(0.07-1.01)$ $\mathrm{mg} / \mathrm{L})$ compared with survivors $(0.07$ (0.03-0.20) $\mathrm{mg} / \mathrm{L} ; P$ $<0.001$ ) (Figure 2b). For patients with sepsis, the uCysC concentrations were higher in survivors (8.61 (1.42-16.7) $\mathrm{mg} / \mathrm{L})$ compared with non-survivors (1.96 (0.21-8.87) $\mathrm{mg} / \mathrm{L})$, although the difference did not reach significance $(P=0.097)$.

\section{uCysC and pCysC as diagnostic and predictive markers for AKI in sepsis}

Within sepsis patients only, the diagnostic performance of $\mathrm{uCysC}$ for AKI was not significant $(\mathrm{AUC}=0.61$; $\mathrm{CI}$, 0.48 to $0.73 ; P=0.11$, whereas the $\mathrm{pCys} C$ remained significant (AUC $=0.75$; CI, 0.63 to $0.86 ; P<0.0001$ ). In the subgroup of sepsis patients without AKI on entry, pCysC was not predictive of AKI within 48 hours, but uCysC was predictive $(\mathrm{AUC}=0.71 ; \mathrm{CI}, 0.55$ to 0.86$)$. $\mathrm{uCys} C$ was not predictive of AKI in patients without sepsis (AUC = 0.45 ; CI, 0.36 to 0.53 )

\section{Time course of uCysC}

Patients with sepsis had high concentrations of uCysC on admission to the ICU (Figure 3) that showed an exponential decline of $\mathrm{uCys} C$ over 7 days in those both with and without AKI. These may be explained by a response to treatment. In contrast, in the absence of sepsis, patients had lower mean uCysC concentrations on admission, in the presence or in the absence of AKI. In nonsepsis patients, the $\mathrm{uCysC}$ concentration increased after admission. In those with AKI, it peaked at $\sim 63$ hours after admission. This may reflect continued development of AKI in patients without sepsis, or it may reflect delayed excretion of substances competing for tubular reabsorption with uCysC, such as albumin, or it may be unrelated.

In sepsis patients without AKI on entry, those in whom AKI developed within 48 hours initially had higher $\mathrm{uCysC}$ concentrations than did those in whom AKI did not develop (Figure 4). After 72 hours, the concentrations of the two subgroups were indistinguishable.

\section{Discussion}

An expectation exists that future early diagnosis of AKI will use a panel of biomarkers [14,33]. It is therefore important to assess potential biomarkers in a variety of clinical settings and in the presence of different co-mor- 


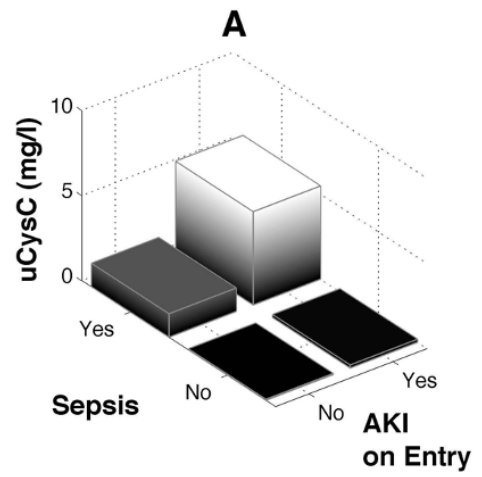

B

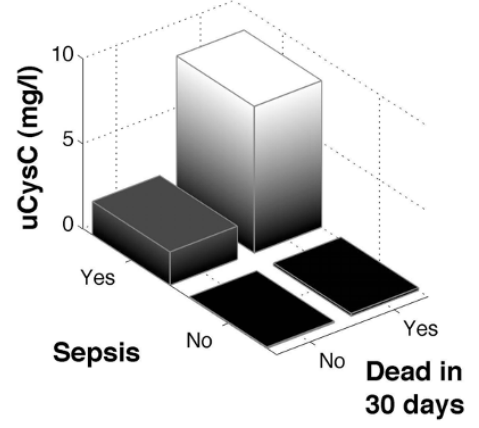

Figure $\mathbf{2}$ Median urinary cystatin C differences. (a) Patients with and without acute kidney injury (AKI) and with and without sepsis on admission to ICU; and (b) 30-day survivors and nonsurvivors.

bidities. This study prospectively assessed cystatin $\mathrm{C}$, a biomarker present in both urine and plasma, in a typical heterogeneous adult ICU population. The study demon-

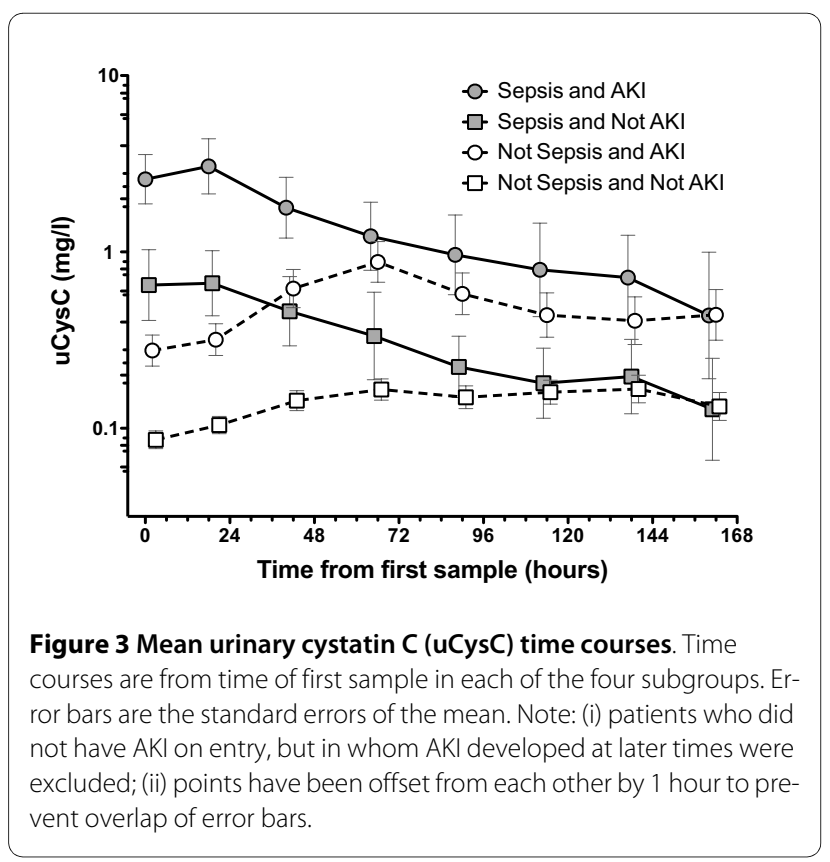

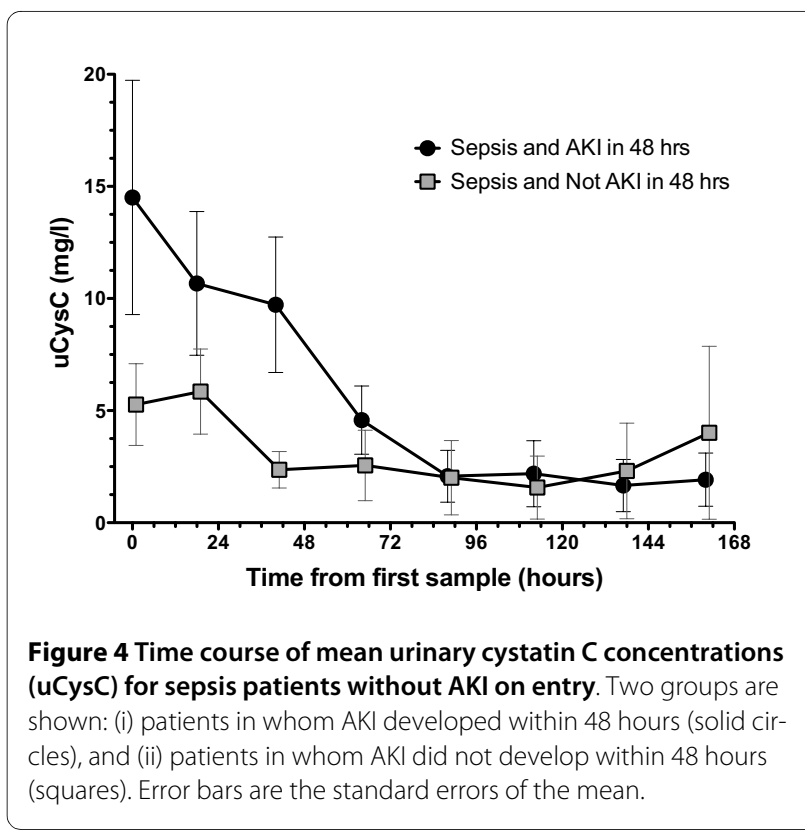

strated an unexpected association between $\mathrm{uCysC}$ and sepsis. Patients with sepsis had markedly elevated uCysC concentrations. An elevated $\mathrm{uCysC}$ was independently associated with AKI and mortality. These associations remained when adjusted for covariates, including age, gender, hypotension, APACHE II subcategory scores, $\mathrm{pCysC}, \mathrm{pCr}$, and $\mathrm{uCr}$.

As anticipated, $\mathrm{uCysC}$ was associated with $\mathrm{AKI}$ on ICU admission. As a stand-alone diagnostic marker with an AUC of only 0.70, its utility is limited. However, the AUC was enhanced after adjustment for $\mathrm{pCysC}, \mathrm{uCr}$, age, hypotension, and APACHE II subcategory scores: respiratory rate, white blood cell (WBC) count, and arterial $\mathrm{pH}$. Because low-molecular-weight proteins, such as cystatin $\mathrm{C}$, are freely filtered through the glomerulus, and completely reabsorbed in the proximal tubule under normal conditions [34], any increase in urinary excretion should represent tubular dysfunction or damage or the result of increased competition for tubular reabsorption through megalin receptors (see later and [35]). In the acute situation, we postulate that it is more likely that the presence of $\mathrm{uCysC}$ is due to tubular injury, as has been demonstrated by others $[21,24,36]$. Thus, tubular dysfunction or damage may explain both proteinuria and AKI in sepsis $[37,38]$.

Sepsis is a well-established cause of AKI in critically ill patients, with inflammatory mediators and cytokines possibly contributing to tubular apoptosis [6,39-41]. In ICU patients, sepsis is reported as a contributing factor to AKI in $43 \%[6,42]$ and the primary cause in $32 \%$ [6]. Most inflammatory responses during sepsis have been associated with microalbuminuria or proteinuria [43-45]. Albuminuria and proteinuria in the absence of renal diseases 
are increasingly recognized as risk factors for cardiovascular mortality [46]. Filtered albumin can compete with filtered cystatin $\mathrm{C}$ for reabsorption and hence increase $\mathrm{uCysC}$. Limited evidence for this is found in a rat model with proteinuria [35]. In the present study, $\mathrm{pCysC}$ was not independently associated with sepsis, suggesting that excess filtration of cystatin $\mathrm{C}$ (overload proteinuria) was not responsible for the increase in uCysC. However, as sepsis and AKI both can cause proteinuria $[25,47,48]$, it is possible that the late peak in uCysC excretion reflects competition for tubular uptake in the presence of induced albuminuria or proteinuria. Because of the association of $\mathrm{CysC}$ with tubular proteinuria, an increased $\mathrm{uCysC}$ is predicted to be more strongly associated with patients with diabetes and perhaps hypertension. We found no evidence for this (data not shown), although $\mathrm{pCysC}$ and $\mathrm{pCr}$ were higher on admission $(P<0.001)$ in patients with a history of hypertension.

Few studies have been performed of urinary biomarkers of AKI in sepsis. Few clinical studies of urinary biomarkers in AKI have investigated sepsis in their cohorts [47]. Parikh et al. [17] observed increased urinary IL-18 in sepsis patients. Recently, it was shown that plasma and urine neutrophil gelatinase-associated lipocalin (NGAL) concentrations on entry to the ICU were significantly higher in patients with septic AKI than in those with nonseptic AKI [49]. Whereas low-molecular-weight proteins in the urine are predictive of AKI [50,51], their predictive value in sepsis patients is unclear. We speculate that the presence of sepsis in the study cohort may somehow modify the diagnostic or predictive performance of biomarkers for AKI. For example, the AUC for UNGAL for prediction of AKI within 48 hours was 0.64 in an ICU study in which $41 \%$ of patients had sepsis [52], whereas in patients with multitrauma on entry to the ICU, the AUC was 0.977 [53]. This suggests a need to consider the proportion of patients with sepsis in the study population when assessing the utility of a urinary biomarker of AKI.

In patients without sepsis, $\mathrm{uCysC}$ was moderately diagnostic of AKI on entry to the ICU, but was not predictive of AKI within 48 hours in the subgroup without AKI on entry. Although the median $\mathrm{uCysC}$ was highest in patients with sepsis and AKI on entry, the distribution was not significantly different from that in sepsis patients without AKI. This lack of difference may have resulted from the increase in uCysC concentrations in sepsis, masking any increase caused by AKI. This may occur if the time course of $\mathrm{uCysC}$ after development of AKI is so short that, by the time patients reached the ICU, the effect of AKI on uCysC concentration was small compared with the effect of sepsis. This is illustrated schematically in Figure 5. This may explain why uCysC was predictive of AKI in sepsis patients and showed a decline in concentration over a 2- to 3-day period until concen- trations of those with and without AKI could not be distinguished (Figure 4). It was shown in an animal model that sepsis reduces the production of $\mathrm{pCr}$ [54]. This would reduce the sensitivity of $\mathrm{uCysC}$ as a marker for AKI when pCr-based definitions of AKI are applied. For $\mathrm{uCysC}$ to be useful as a marker of AKI in sepsis patients will require a cut point specific to sepsis and, ideally, a plasma creatinine-independent method of assessing reduced GFR.

Another novel finding of this study was the observation that $\mathrm{uCys} C$ predicted death within 30 days of admission to the ICU, independent of sepsis and AKI. The risk of death was more than doubled in patients with $\mathrm{uCysC}>0.1$ $\mathrm{mg} / \mathrm{dL}$. Identification of risk factors for death in the early stages of ICU admission may facilitate future intervention to prevent poor outcomes (for example, through increased supportive care or therapeutic intervention) [55]. A note of caution is warranted, given that the exclusion criteria of EARLYARF excluded those who, on admission, were thought likely to die within 72 hours. Retention of such patients in a future study is needed to avoid selection bias in defining the risk of death associated with an elevated $\mathrm{uCysC}$.

Although this is the first study to show that $\mathrm{uCysC}$ is predictive of death, $\mathrm{pCysC}$ has been shown to be as independent risk factor for mortality in the elderly [23] and in patients with chronic kidney diseases (CKDs) [56]. The association of $\mathrm{pCysC}$ with mortality is independent of AKI [22].

Several limitations to our study exist. The study was designed not as an observational study of sepsis biomark-

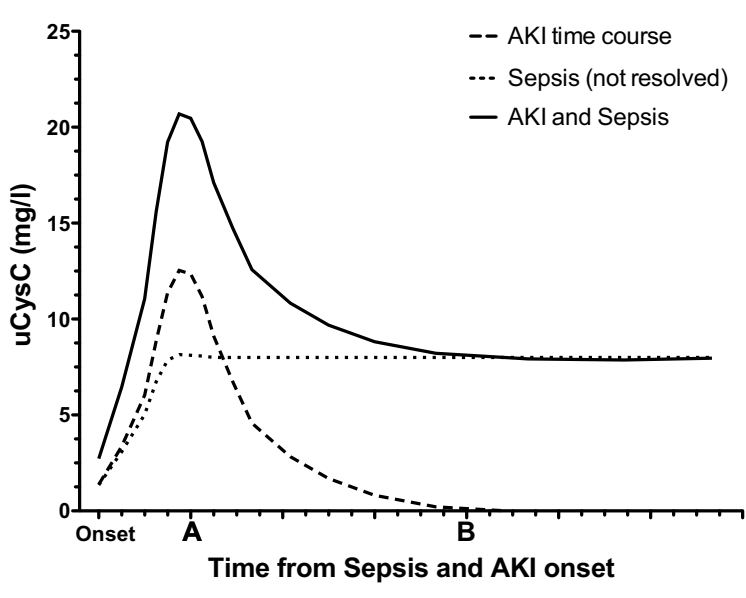

Figure 5 Hypothetical time course of uCysC for a patient with both sepsis and AKI. The effect of AKI (dashed line) and sepsis (dotted line) on uCysC are additive (solid line). The shorter time course of AKI compared with the ongoing elevation in UCysC with ongoing sepsis may explain why $\mathrm{UCys} C$ was predictive of AKI at some times (for example, time point A) but not others (for example, time point B). 
ers, but rather of AKI biomarkers on which a post hoc analysis of the influence of sepsis was performed. Sepsis was not predefined, and so caution should be applied when making comparisons with other studies, especially as the proportion of patients who died did not differ in the sepsis and nonsepsis cohorts. Because medications, including corticosteroids, may affect plasma cystatin $\mathrm{C}$ [57], uCysC concentrations could theoretically be affected. The first sample in the ICU was taken before corticosteroid administration, and $\mathrm{uCysC}$ was independently associated with AKI, sepsis, and mortality, even when $\mathrm{pCysC}$ concentrations were accounted for, arguing against any medication-induced change. In addition, the cohort did not include patients with very high creatinine on admission, thereby excluding some patients with CKD and some with severe AKI. The potential utility of uCysC to predict the need for renal-replacement therapy should be studied in a cohort that does not exclude patients with high creatinine concentrations. Finally, exclusion of patients not expected to remain in the ICU for more than 24 hours limits the study to the more seriously ill.

The finding that $\mathrm{uCysC}$ was predictive of sepsis should be considered hypothesis forming. The future utility of $\mathrm{uCys} C$ depends on its ability to provide earlier diagnostic information than blood cultures for sepsis or additional information on kidney injury or both. In addition to diagnostic or prognostic utility, biomarkers of sepsis may be valuable to guide therapy and evaluate recovery [58]. $\mathrm{uCys} C$ may play a role in both, first by helping to avoid nephrotoxins in the presence of AKI, and second, as a marker of recovery (Figures 3 and 4). Intuitively, it seems unlikely that $\mathrm{uCysC}$ will be specific for sepsis, because the mechanism of increase is likely to reflect impaired renal transport, which is either competitive (as with albuminuria) or noncompetitive (due to direct tubular injury, in which case, the diagnostic and predictive value should be the same for both AKI and sepsis). Ultimately, and assuming the significance of an increased $\mathrm{uCysC}$ can be validated in other studies, an increased $\mathrm{uCysC}$ may assist with performing triage to renoprotective treatment in much the same way as an increased serum lactate in patients meeting SIRS criteria indicated assignment to early goal-directed therapy [59].

\section{Conclusions}

Detection of AKI and sepsis and accurate prediction of mortality risk are important parameters in critically ill patients. These studies highlight the potential of uCysC as a biomarker of AKI in nonsepsis patients, of AKI severity, as a biomarker of sepsis, and finally as a prognostic biomarker of mortality, independent of both sepsis and AKI. Because the method of measuring $\mathrm{uCys} C$ is rapid, precise, simple, and readily available in clinical chemistry laboratories [60], uCysC appears to have con- siderable potential as a biomarker. These conclusions require independent validation and should encourage further exploration of the time course and reliability role of uCysC in the critically ill.

\section{Key Messages}

- In the ICU, urinary cystatin $\mathrm{C}$ is diagnostic of acute kidney injury.

- In the ICU, urinary cystatin $\mathrm{C}$ is independently diagnostic of sepsis.

- In the ICU, urinary cystatin C predicts AKI in the presence of sepsis.

- In the ICU, urinary cystatin $\mathrm{C}$ predicts death.

- In the ICU, AKI biomarker studies should exclude confounding by sepsis.

\section{Abbreviations}

AKI: Acute kidney injury; AKIN: Acute Kidney Injury Network; APACHE: Acute Physiology and Chronic Health Evaluation; AUC: area under the receiver operator characteristic curve; Cl: confidence interval (95\%); EARLYARF: The Early Acute Renal Failure trial; GFR: glomerular filtration rate; ICU: intensive care unit; IL-18: interleukin 18; MDRD: modification of diet in renal disease; NGAL: neutrophil gelatinase associated lipocalin; OR: odds ratio; pCysC: plasma cystatin C; pCr: plasma creatinine; ROC: receiver operator characteristic; SD: standard deviation; SIRS: systemic inflammatory response syndrome; SOFA: Sepsis-related Organ Failure Assessment; uCr: urinary creatinine; uCysC: urinary cystatin C; WBC: white blood cell.

\section{Competing interests}

The authors declare that they have no competing interests.

\section{Authors' contributions}

MN participated in the acquisition of the data, performed statistical analysis, and drafted the manuscript. JP managed the acquisition of data, conceived and performed some of the statistical analysis, and drafted the manuscript. RW participated in the design of the study, acquisition of data, and revision of the draft for critical content. JW participated in the design of the study, helped set up assays, and revised the draft for critical content. GS participated in the design of the study, acquisition of data, and revision of the draft for critical content. CF participated in the design of the EARLYARF trial and in the statistical analysis of the data. ZE conceived the EARLYARF study and the concept of measuring $\mathrm{UCys} C$ and participated in the study design, interpretation of results, and revision of the draft.

\section{Acknowledgements}

We thank the staff of the ICUs of Dunedin and Christchurch hospitals; and John Dean, Jan Mehrtens, Jill Robinson, and Robyn Hutchison for assisting with data collection. The study was supported by the Health Research Council of New Zealand grant 05/131 (Early intervention in acute renal failure), except for the assays of cystatin C, which were supported independently by the Christchurch Kidney Research Group. Maryam Nejat was supported by a University of Otago postgraduate scholarship. The study was presented in part in abstract form (poster) at The American Society of Nephrology, 42nd Annual Meeting and Scientific Exposition, San Diego, October 27 to November 1, 2009.

\section{Author Details}

${ }^{1}$ Christchurch Kidney Research Group, Department of Medicine, University of Otago Christchurch, Riccarton Avenue, Christchurch 8140, New Zealand, 2Department of Medicine and Surgery, University of Otago, Leith Walk, Dunedin 9054, New Zealand and 3Intensive Care Unit, Christchurch Hospital, Riccarton Avenue, Christchurch 8140, New Zealand

Received: 11 November 2009 Revisions Requested: 17 February 2010 Accepted: 12 May 2010 Published: 12 May 2010 


\section{References}

1. Cruz DN, Bolgan I, Perazella MA, Bonello M, de Cal M, Corradi V, Polanco N, Ocampo C, Nalesso F, Piccinni P, Ronco C: North East Italian Prospective Hospital Renal Outcome Survey on Acute Kidney Injury (NEiPHROSAKI): targeting the problem with the RIFLE Criteria. Clin J Am SoC Nephrol 2007, 2:418-425.

2. Ricci Z, Cruz D, Ronco C: The RIFLE criteria and mortality in acute kidney injury: a systematic review. Kidney Int 2008, 73:538-546.

3. Hoste EA, Clermont G, Kersten A, Venkataraman R, Angus DC, De Bacquer $D$, Kellum JA: RIFLE criteria for acute kidney injury are associated with hospital mortality in critically ill patients: a cohort analysis. Crit Care 2006, 10:R73.

4. Bagshaw SM, George C, Dinu I, Bellomo R: A multi-centre evaluation of the RIFLE criteria for early acute kidney injury in critically ill patients. Nephrol Dial Transplant 2008, 23:1203-1210.

5. Ostermann M, Chang RW: Acute kidney injury in the intensive care unit according to RIFLE. Crit Care Med 2007, 35:1837-1843.

6. Bagshaw SM, George C, Bellomo R: Early acute kidney injury and sepsis: a multicentre evaluation. Crit Care 2008, 12:R47.

7. Schrier RW, Wang W: Acute renal failure and sepsis. N Engl J Med 2004, 351:159-169.

8. Alberti C, Brun-Buisson C, Burchardi H, Martin C, Goodman S, Artigas A Sicignano A, Palazzo M, Moreno R, Boulme R, Lepage E, Le Gall R: Epidemiology of sepsis and infection in ICU patients from an international multicentre cohort study. Intensive Care Med 2002 28:108-121.

9. Vincent JL, Sakr Y, Sprung CL, Ranieri VM, Reinhart K, Gerlach H, Moreno R, Carlet J, Le Gall JR, Payen D: Sepsis in European intensive care units: results of the SOAP study. Crit Care Med 2006, 34:344-353.

10. Linde-Zwirble WT, Angus DC: Severe sepsis epidemiology: sampling, selection, and society. Crit Care 2004, 8:222-226.

11. Heyland DK, Hopman W, Coo H, Tranmer J, McColl MA: Long-term health-related quality of life in survivors of sepsis: Short Form 36: a valid and reliable measure of health-related quality of life. Crit Care Med 2000, 28:3599-3605.

12. Westhuyzen J: Cystatin C: a promising marker and predictor of impaired renal function. Ann Clin Lab Sci 2006, 36:387-394.

13. Nejat M, Pickering JW, Walker RJ, Endre ZH: Rapid detection of acute kidney injury by plasma cystatin $C$ in the intensive care unit. Nephrol Dial Transplant 2010 in press.

14. Endre $\mathrm{ZH}$ : Acute kidney injury: definitions and new paradigms. Adv Chronic Kidney Dis 2008, 15:213-221.

15. Herget-Rosenthal S, Marggraf G, Husing J, Goring F, Pietruck F, Janssen O, Philipp T, Kribben A: Early detection of acute renal failure by serum cystatin C. Kidney Int 2004, 66:1115-1122.

16. Liangos $\mathrm{O}$, Perianayagam MC, Vaidya VS, Han WK, Wald R, Tighiouart $H$ MacKinnon RW, Li L, Balakrishnan VS, Pereira BJ, Bonventre JV, Jaber BL: Urinary $\mathrm{N}$-acetyl-beta-(D)-glucosaminidase activity and kidney injury molecule-1 level are associated with adverse outcomes in acute renal failure. J Am Soc Nephrol 2007, 18:904-912.

17. Parikh CR, Abraham E, Ancukiewicz M, Edelstein CL: Urine IL-18 is an early diagnostic marker for acute kidney injury and predicts mortality in the intensive care unit. J Am Soc Nephro/ 2005, 16:3046-3052.

18. Han WK, Bailly V, Abichandani R, Thadhani R, Bonventre JV: Kidney injury molecule-1 (KIM-1): a novel biomarker for human renal proximal tubule injury. Kidney Int 2002, 62:237-244

19. Westhuyzen J, Endre ZH, Reece G, Reith DM, Saltissi D, Morgan TJ: Measurement of tubular enzymuria facilitates early detection of acute renal impairment in the intensive care unit. Nephrol Dial Transplant 2003, 18:543-551.

20. Coca SG, Yalavarthy R, Concato J, Parikh CR: Biomarkers for the diagnosis and risk stratification of acute kidney injury: a systematic review. Kidney Int 2008, 73:1008-1016.

21. Koyner JL, Bennett MR, Worcester EM, Ma Q, Raman J, Jeevanandam V, Kasza KE, O'Connor MF, Konczal DJ, Trevino S, Devarajan P, Murray PT: Urinary cystatin $C$ as an early biomarker of acute kidney injury following adult cardiothoracic surgery. Kidney Int 2008, 74:1059-1069.

22. Bell M, Granath F, Martensson J, Lofberg E, Ekbom A, Martling CR: Cystatin $C$ is correlated with mortality in patients with and without acute kidney injury. Nephrol Dial Transplant 2009, 24:3096-3102.

23. Shlipak MG, Wassel Fyr CL, Chertow GM, Harris TB, Kritchevsky SB, Tylavsky FA, Satterfield S, Cummings SR, Newman AB, Fried LF: Cystatin C and mortality risk in the elderly: the health, aging, and body composition study. J Am Soc Nephrol 2006, 17:254-261.

24. Conti M, Moutereau S, Zater M, Lallali K, Durrbach A, Manivet $P$, Eschwege $P$, Loric S: Urinary cystatin $C$ as a specific marker of tubular dysfunction. Clin Chem Lab Med 2006, 44:288-291.

25. Herget-Rosenthal S, van Wijk JA, Brocker-Preuss M, Bokenkamp A: Increased urinary cystatin $C$ reflects structural and functional renal tubular impairment independent of glomerular filtration rate. Clin Biochem 2007, 40:946-951.

26. Endre ZH, Walker RJ, Pickering JW, Shaw GM, Frampton CM, Henderson SJ, Hutchison R, Mehrtens J, Robinson JM, Schollum JBW, Westhuyzen J, Celi LA, McGinley R, Campbell IJ, George PM: Early intervention with erythropoietin does not affect the outcome of acute kidney injury (the EARLYARF trial). Kidney Int 2010, 77:1020-1030.

27. Australian New Zealand Clinical Trials Registry [http:// www.anzctr.org.au]

28. Erlandsen EJ, Randers E, Kristensen JH: Evaluation of the Dade Behring N Latex Cystatin C assay on the Dade Behring Nephelometer II System. Scand J Clin Lab Invest 1999, 59:1-8.

29. Mehta RL, Kellum JA, Shah SV, Molitoris BA, Ronco C, Warnock DG, Levin A: Acute Kidney Injury Network: report of an initiative to improve outcomes in acute kidney injury. Crit Care 2007, 11:R31.

30. Pickering JW, Frampton CM, Endre ZH: Evaluation of trial outcomes in acute kidney injury by creatinine modeling. Clin J Am Soc Nephrol 2009, 4:1705-1715.

31. Pickering J, Endre ZH: Back-calculating baseline creatinine with MDRD misclassifies Acute Kidney Injury in the intensive care unit. Clin J Am Soc Nephrol 2010 in press.

32. Uchida K, Gotoh A: Measurement of cystatin-C and creatinine in urine. Clin Chim Acta 2002, 323:121-128.

33. Parikh CR, Devarajan P: New biomarkers of acute kidney injury. Crit Care Med 2008, 36:S159-165.

34. Maack T, Johnson V, Kau ST, Figueiredo J, Sigulem D: Renal filtration, transport, and metabolism of low-molecular-weight proteins: a review. Kidney Int 1979, 16:251-270.

35. Thielemans N, Lauwerys R, Bernard A: Competition between albumin and low-molecular-weight proteins for renal tubular uptake in experimental nephropathies. Nephron 1994, 66:453-458.

36. Herget-Rosenthal S, Poppen D, Husing J, Marggraf G, Pietruck F, Jakob HG, Philipp T, Kribben A: Prognostic value of tubular proteinuria and enzymuria in nonoliguric acute tubular necrosis. Clin Chem 2004, 50:552-558.

37. Richmond JM, Sibbald WJ, Linton AM, Linton AL: Patterns of urinary protein excretion in patients with sepsis. Nephron 1982, 31:219-223.

38. Wan L, Bagshaw SM, Langenberg C, Saotome T, May C, Bellomo R: Pathophysiology of septic acute kidney injury: what do we really know? Crit Care Med 2008, 36:S198-203.

39. Yegenaga I, Hoste E, Van Biesen W, Vanholder R, Benoit D, Kantarci G, Dhondt A, Colardyn F, Lameire N: Clinical characteristics of patients developing ARF due to sepsis/systemic inflammatory response syndrome: results of a prospective study. Am J Kidney Dis 2004, 43:817-824

40. Hoste EA, Lameire NH, Vanholder RC, Benoit DD, Decruyenaere JM Colardyn FA: Acute renal failure in patients with sepsis in a surgical ICU: predictive factors, incidence, comorbidity, and outcome. J Am SoC Nephrol 2003, 14:1022-1030.

41. Jo SK, Cha DR, Cho WY, Kim HK, Chang KH, Yun SY, Won NH: Inflammatory cytokines and lipopolysaccharide induce Fas-mediated apoptosis in renal tubular cells. Nephron 2002, 91:406-415

42. Bagshaw SM, Uchino S, Bellomo R, Morimatsu H, Morgera S, Schetz M, Tan I, Bouman C, Macedo E, Gibney N, Tolwani A, Oudemans-van Straaten HM, Ronco C, Kellum JA: Septic acute kidney injury in critically ill patients: clinical characteristics and outcomes. Clin J Am Soc Nephrol 2007, 2:431-439.

43. Rinaldi S, Peeters PH, Bezemer ID, Dossus L, Biessy C, Sacerdote C, Berrino F, Panico S, Palli D, Tumino R, Khaw KT, Bingham S, Allen NE, Key T, Jensen MK, Overvad K, Olsen A, Tjonneland A, Amiano P, Ardanaz E, Agudo A, Martinez-Garcia C, Quiros JR, Tormo MJ, Nagel G, Linseisen J, Boeing H, Schulz M, Grobbee DE, Bueno-de-Mesquita HB, et al:: Relationship of alcohol intake and sex steroid concentrations in blood in pre- and post-menopausal women: the European Prospective Investigation into Cancer and Nutrition. Cancer Causes Control 2006, 17:1033-1043. 
44. De Gaudio AR, Adembri C, Grechi S, Novelli GP: Microalbuminuria as an early index of impairment of glomerular permeability in postoperative septic patients. Intensive Care Med 2000, 26:1364-1368.

45. Thorevska N, Sabahi R, Upadya A, Manthous C, Amoateng-Adjepong Y: Microalbuminuria in critically ill medical patients: prevalence, predictors, and prognostic significance. Crit Care Med 2003, 31:1075-1081.

46. Brantsma AH, Bakker SJ, de Zeeuw D, de Jong PE, Gansevoort RT: Extended prognostic value of urinary albumin excretion for cardiovascular events. J Am Soc Nephrol 2008, 19:1785-1791.

47. Bagshaw SM, Langenberg C, Haase M, Wan L, May CN, Bellomo R: Urinary biomarkers in septic acute kidney injury. Intensive Care Med 2007, 33:1285-1296.

48. van Meurs M, Kurniati NF, Wulfert FM, Asgeirsdottir SA, de Graaf IA, Satchell SC, Mathieson PW, Jongman RM, Kumpers P, Zijlstra JG, Heeringa $P$, Molema G: Shock-induced stress induces loss of microvascular endothelial Tie2 in the kidney which is not associated with reduced glomerular barrier function. Am J Physiol Renal Physiol 2009, 297:F272-281

49. Bagshaw SM, Bennett M, Haase M, Haase-Fielitz A, Egi M, Morimatsu H, D'Amico G, Goldsmith D, Devarajan P, Bellomo R: Plasma and urine neutrophil gelatinase-associated lipocalin in septic versus non-septic acute kidney injury in critical illness. Intensive Care Med 2010, 36:452-461.

50. Endre ZH, Westhuyzen J: Early detection of acute kidney injury: emerging new biomarkers. Nephrology (Carlton) 2008, 13:91-98.

51. Guder WG, Hofmann W: Clinical role of urinary low molecular weight proteins: their diagnostic and prognostic implications. Scand J Clin Lab Invest Supp/ 2008, 241:95-98

52. Siew ED, Ware LB, Gebretsadik T, Shintani A, Moons KG, Wickersham N, Bossert F, Ikizler TA: Urine neutrophil gelatinase-associated lipocalin moderately predicts acute kidney injury in critically ill adults. J Am Soc Nephrol 2009, 20:1823-1832.

53. Makris K, Markou N, Evodia E, Dimopoulou E, Drakopoulos I, Ntetsika K, Rizos D, Baltopoulos G, Haliassos A: Urinary neutrophil gelatinaseassociated lipocalin (NGAL) as an early marker of acute kidney injury in critically ill multiple trauma patients. Clin Chem Lab Med 2009, 47:79-82.

54. Doi K, Yuen PS, Eisner C, Hu X, Leelahavanichkul A, Schnermann J, Star RA: Reduced production of creatinine limits its use as marker of kidney injury in sepsis. J Am Soc Nephrol 2009, 20:1217-1221.

55. Bagshaw SM, Laupland KB, Doig CJ, Mortis G, Fick GH, Mucenski M, Godinez-Luna T, Svenson LW, Rosenal T: Prognosis for long-term survival and renal recovery in critically ill patients with severe acute renal failure: a population-based study. Crit Care 2005, 9:R700-709.

56. Menon V, Shlipak MG, Wang X, Coresh J, Greene T, Stevens L, Kusek JW, Beck GJ, Collins AJ, Levey AS, Sarnak MJ: Cystatin C as a risk factor for outcomes in chronic kidney disease. Ann Intern Med 2007, 147:19-27.

57. Risch L, Herklotz R, Blumberg A, Huber AR: Effects of glucocorticoid immunosuppression on serum cystatin $C$ concentrations in renal transplant patients. Clin Chem 2001, 47:2055-2059.

58. Pierrakos C, Vincent JL: Sepsis biomarkers: a review. Crit Care 2010, $14: R 15$.

59. Rivers E, Nguyen B, Havstad S, Ressler J, Muzzin A, Knoblich B, Peterson E, Tomlanovich M: Early goal-directed therapy in the treatment of severe sepsis and septic shock. N Engl J Med 2001, 345:1368-1377.

60. Herget-Rosenthal S, Feldkamp T, Volbracht L, Kribben A: Measurement of urinary cystatin $C$ by particle-enhanced nephelometric immunoassay: precision, interferences, stability and reference range. Ann Clin Biochem 2004, 41:111-118.

\section{doi: $10.1186 /$ cc9014}

Cite this article as: Nejat et al., Urinary cystatin C is diagnostic of acute kidney injury and sepsis, and predicts mortality in the intensive care unit Critical Care 2010, 14:R85

\section{Submit your next manuscript to BioMed Central} and take full advantage of:

- Convenient online submission

- Thorough peer review

- No space constraints or color figure charges

- Immediate publication on acceptance

- Inclusion in PubMed, CAS, Scopus and Google Scholar

- Research which is freely available for redistribution

Submit your manuscript at www.biomedcentral.com/submit
C BioMed Central 